\title{
Special issue: Nucleoside antibiotics, polyoxin and beyond
}

\author{
Hiroyuki Osada $\mathbb{1}^{1}$
}

Received: 7 July 2019 / Accepted: 10 September 2019 / Published online: 27 November 2019

(c) The Author(s), under exclusive licence to the Japan Antibiotics Research Association 2019

Nucleoside antibiotics have long been known as secondary metabolites of mushrooms, microorganisms, and plants. Because the chemical structures of the nucleoside antibiotics resemble those of nucleic acids, their main mechanism of action is related to the inhibition of nucleic acid synthesis. An example is the antitumor compound, cordycepin, which was isolated in the 1950s [1]. However, as more of these compounds were discovered, other types of mechanisms were also found. Some compounds act as an ATP analog and inhibit signal transduction systems involving various phosphorylation reactions [2]. Others act as an analog of an intermediate of the sugar chain biosynthesis and inhibit cell wall synthesis [3]. Therefore, nucleoside antibiotics have various possible applications such as antibacterial, antifungal, anticancer, or herbicidal agents to name a few. Using nucleoside antibiotics as a query in PubMed, more than 17,000 articles have been published since the cordycepin report (Fig. 1).

Although many nucleoside antibiotics have been put to practical use as pharmaceuticals and agrochemicals, blasticidin $S[4,5]$ and the polyoxins $[6,7]$ are recognized as the forerunners of agricultural antibiotics. Before the 1960s, mercury-based pesticides were conventionally used for the rice blast disease, but because of its high toxicity, the screening of alternative fungicides was carried out. In 1958, blasticidin S was isolated from Streptomyces griseochromogenus. It was demonstrated to be a protein synthesis inhibitor against pathogenic fungi and was marketed in 1961 as the world's first agricultural

Hiroyuki Osada

cb-secretary@ml.riken.jp

1 Chemical Biology Research Group RIKEN Center for Sustainable Resource Science, Hirosawa 2-1, Wako-shi, Saitama 351-0198, Japan antibiotic. Along with blasticidin $\mathrm{S}$ as an inhibitor for the rice blast disease, inhibitors against the rice sheath blight disease have also been explored. In 1965, a novel nucleoside compound, polyoxin [6], was isolated from Streptomyces cacaoi by Suzuki and Isono and it was put on the market in 1967. It has a similar structure to chitin's synthetic intermediate (UDP- $N$-acetylglucosamine), which is an essential cell wall component of plant pathogenic fungi [7]. When polyoxin is taken up by the fungi, it mimics a chitin intermediate and leads to the inhibition of chitin synthesis.

On the other hand, Tamura and Takatsuki of the University of Tokyo isolated tunicamycin from Streptomyces lysosperficus in the course of the screening of antiviral agents [8-10]. Its structure is similar to the reaction complex of UDP- $N$-acetylglucosamine and dolichol phosphate; thus, tunicamycin mimics the intermediate of UDP- $N$-acetylglucosamine and dolichol phosphate and blocks the $N$-glycosylation of glycoproteins in mammalian cells. In bacteria, tunicamycin [11] inhibits the UDP- $N$-acetylmuramoyl-pentapeptide:undecaprenol-phosphate phospho- $N$-acetylmuramoyl-pentapeptide-transferase (MraY) that catalyzes the early stage in peptidoglycan cell wall assembly [12]. Although tunicamycin has not been put to practical use as a medicine, it is widely used as a reagent for research, such as studies on endoplasmic reticulum stress and autophagy [13, 14].

The above-mentioned pioneering studies on nucleoside antibiotics have been published in this journal. Last year, the Sumiki-Umezawa Memorial Award was given to two researchers (K. Kimura and M. Igarashi) who were involved in the research of the antituberculosis nucleoside antibiotics, liposidomycin [15-17], and caprazamycin [18, 19]. In addition, many researchers have been involved in the chemical synthesis and biosynthesis of nucleoside antibiotics. Using this background, this special issue is compiled as a perspective on the future direction of nucleoside antibiotics research. 
Fig. 1 The number of scientific papers reporting nucleoside related subjects

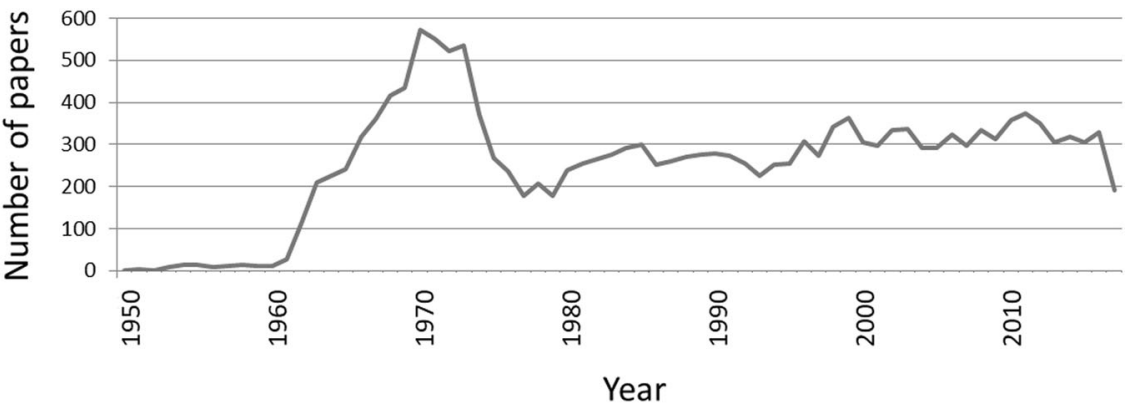

\section{Compliance with ethical standards}

Conflict of interest The authors declare that they have no conflict of interest.

Publisher's note Springer Nature remains neutral with regard to jurisdictional claims in published maps and institutional affiliations.

\section{References}

1. Cunningham KG, Manson W, Spring FS, Hutchinson SA. Cordycepin, a metabolic product isolated from cultures of Cordyceps militaris (Linn.) Link. Nature. 1950;166:949.

2. Osada H, Sonoda T, Tsunoda K, Isono K. A new biological role of sangivamycin; Inhibition of protein kinases. J Antibiot. 1989;42:102-6.

3. Brandish PE, et al. Modes of action of tunicamycin, liposidomycin $\mathrm{B}$, and mureidomycin A: inhibition of phospho- $N$-acetylmuramylpentapeptide translocase from Escherichia coli. Antimicrob Agents Chemother. 1996;40:1640-4.

4. Takeuchi S, Hirayama K, Ueda K, Sakai H, Yonehara H. Blasticidin S, a new antibiotic. J Antibiot. 1958;11:1-5.

5. Huang KT, Misato T, Asuyama H. Selective toxicity of blasticidin $\mathrm{S}$ to Piricularia oryzae and Pellicularia sasakii. J Antibiot. 1964;17:71-74.

6. Suzuki S, et al. A new antibiotic, polyoxin A. J Antibiot. 1965;18:131.

7. Isono K, Asahi K, Suzuki S. Studies on polyoxins, antifungal antibiotics. 13. The structure of polyoxins. J Am Chem Soc. 1969;91:7490-505.

8. Takatsuki A, Arima K, Tamura G. Tunicamycin, a new antibiotic. I isolation and characterization of tunicamycin A. J Antibiot. 1971;24:215-23.
9. Takatsuki A, Tamura G. Tunicamycin, a new antibiotic. II some biological properties of the antiviral activity of tunicamycin. $\mathrm{J}$ Antibiot. 1971;24:224-31.

10. Takatsuki A, Tamura G. Tunicamycin, a new antibiotic. III reversal of the antiviral activity of tunicamycin by aminosugars and their derivatives. J Antibiot. 1971;24:232-8.

11. Ito T, Takatsuki A, Kawamura K, Sato K, Tamura G. Isolation and structures of components tunicamycin. Agric Biol Chem. 1980;44:695-8.

12. Ikeda M, Wachi M, Jung HK, Ishino F, Matsuhashi $M$. The Escherichia coli mraY gene encoding UDP- $N$-acetylmuramoylpentapeptide: undecaprenyl-phosphate phospho- $N$-acetylmuramoylpentapeptide transferase. J Bacteriol. 1991;173:1021-6.

13. He L, et al. ATM blocks tunicamycin-induced endoplasmic reticulum stress. FEBS Lett. 2009;583:903-8.

14. $\mathrm{Wu} \mathrm{J}$, et al. Tunicamycin specifically aggravates ER stress and overcomes chemoresistance in multidrug-resistant gastric cancer cells by inhibiting N-glycosylation. J Exp Clin Cancer Res. 2018;37:272.

15. Kimura K, et al. New type of liposidomycin that inhibit bacterial peptidoglycan synthesis and are produced by Streptomyces. I. Producing organism and medium components. J Antibiot. 1998;51:640-6.

16. Kimura $\mathrm{K}$, et al. New type of liposidomycin that inhibit bacterial peptidoglycan synthesis and are produced by Streptomyces. II. Isolation and structure elucidation. $\mathrm{J}$ Antibiot. 1998;51:647-54.

17. Kimura K, et al. Selective inhibition of the bacterial peptidoglycan biosynthesis by the new types of liposidomycins. J Antibiot. 1998;51:1099-104.

18. Igarashi $\mathrm{M}$, et al. Caprazamycin $\mathrm{B}$, a novel anti-tuberculosis antibiotic, from Streptomyces sp. J Antibiot. 2003;56:580-3.

19. Igarashi $\mathrm{M}$, et al. Caprazamycins, novel lipo-nucleoside antibiotics, from Streptomyces sp. II. Structure elucidation of caprazamycins. J Antibiot. 2005;58:327-37. 